MATEC Web of Conferences 13,02037 (2014)

DOI: $10.1051 /$ matecconf/ 20141302037

(C) Owned by the authors, published by EDP Sciences, 2014

\title{
Spray-Wall Impingement of Diesel-CNG Dual Fuel Jet using Schlieren Imaging Technique
}

\author{
Mhadi Abaker Ismael ${ }^{1, a}$, Morgan Remond Heikal² and Masri B. Baharom ${ }^{1}$ \\ ${ }^{1}$ Mechanical Eng. Department, Universiti Technologi PETRONAS, 31750 Tronoh, Perak, Malaysia \\ ${ }^{2}$ Mechanical Eng. Department, Universiti Technologi PETRONAS, 31750 Tronoh, Perak, Malaysia
}

\begin{abstract}
Natural gas is a low cost fuel with high availability in nature. However, it cannot be used by itself in conventional diesel engines due to its low flame speed and high ignition temperature. The addition of a secondary fuel to enhance the mixture formation and combustion process facilitate its wider use as an alternative fuel. An experimental study was performed to investigate the diesel-CNG dual fuel jet-wall impingement. A constant volume optical chamber was designed to facilitate maximum optical access for the study of the jet-wall impingement at different injection pressures, temperatures and injector-wall distances. The bottom plate of the test rig was made of aluminum (piston material) and it was heated up to $500 \mathrm{~K}$ at ambient pressure. An injector driver was used to control the single-hole nozzle diesel injector combined with a natural gas injector. The injection timing of both injectors was synchronized with a camera trigger. The jet-wall impingement of diesel and diesel-CNG dual fuel jets was recorded with a high speed camera using Schlieren imaging technique and associated image processing software. The measurements of the jet radial penetration were higher in diesel-CNG dual fuel while the jet height travel along were higher in the case of diesel single fuel.
\end{abstract}

\section{Introduction}

Internal combustion engines have largely contributed to the global air pollution leading to the deterioration of the environment. Correspondingly, interest is growing to develop the internal combustion engines to reduce the exhaust emissions of the regulated pollutants. Compressed natural gas (CNG), and other gaseous fuels have been widely used as alternative fuels in internal combustion engines because of their potential to maintain engine performance and reduce the emissions of hydrocarbon [1]. The main types of engines using gaseous fuels include premixed charge spark ignition engine, lean burn engine, dual fuel-pilot injection engine, and dual fuel direct injection engine. Successful studies have been carried out on these engines and shown that, the most promising one is the direct injection dual fuel engines in terms of their performance, power output and emissions [2]. The studies also showed that the main concern when using natural gas in conventional compression ignition engines was the difficulty in achieving good auto ignition performance due to the high ignition temperature and low cetane number of the CNG. In addition, the process of injecting

\footnotetext{
a Mhadi Abaker Ismael : xmhadosx@yahoo.com
}

This is an Open Access article distributed under the terms of the Creative Commons Attribution License 2.0, which permits unrestricted use, distribution, and reproduction in any medium, provided the original work is properly cited. 
natural gas directly into the combustion chamber near the top dead center (TDC) is different than that of the injection of diesel fuel under the same condition. The mixing process of the diesel fuel is largely dependent upon the spray characteristics, spray wall impingement, droplet size and evaporation in contrast to the case of gaseous fuels which mix with the air more readily. The structure of the gas injector is also different from that of the liquid injector and the injection pressures are lower resulting in a lower momentum of the jet [3,4]. Improvement of the diesel-CNG dual fuel jet characteristics such as jet tip penetration, jet cone angle, jet velocity and jet-wall impingement in turn determine the diesel-CNG dual fuel combustion process and the associated formation of pollutants. Spray-wall impingement can be characterized into radial penetration along the wall and jet height. Improvement of those characteristics leads to enhance the mixture formation as well as the combustion process.

Over the last decade, studies on spray-wall impingement have been shown to lead to performance improvement of the engine and emissions [3]. Recently, visualization of the macroscopic characteristics of diesel fuel under different injection pressures and wall temperature were experimentally investigated by [4]. The images were recorded using the shadowgraphy technique and analyzed using an image processing system. Their results showed, that the rate of spray tip penetration increased as the injection pressure increased but decreased with the increase in the ambient pressure or temperature. It was also found that the spray cone angle became wider as the ambient pressure or temperature increased. An experimental study was performed to visualizing the effect of fuel spray and its impingement on the cylinder walls and piston head by [5]. The authors used two types of injectors: low pressure $(3 \mathrm{MPa}$ ) and high pressure (up to $10 \mathrm{MPa}$ ). The study found that the effect of spilt injection is maintaining the same amount of fuel used in the single injection system. Their results also showed that the spilt injection was an effective way to reduce the overall wall impingement in the cylinder surfaces.

Besides the work on the diesel fuel sprays, many studies on high pressure gas jets have been conducted using different optical diagnostic techniques. Natural gas jet/wall impingement is considered as a promising way to control and enhance the mixing processes in the combustion chamber. Senooet al. [6] investigated the wall impingement of natural gas jet at high injection pressure using direct-visualization images in a constant volume vessel under different ambient conditions. The authors showed that the jet impingement was affected by the distance between the injector nozzle and the wall as well as the injection pressure. Yu et al. [7] studied the wall-impinging gas jets and mixture formations under low pressure (e.g. 3 and 7 bar) using the PLIF technique. Their results showed that the interaction between the gas jet, wall impingement and surrounding air had a good effect on the mixing process. A high injection pressure led to higher mixing efficiency. The authors concluded that the low-pressure jet wall-impingement was considered a promising approach to enhance the mixing process.

In the present study, the characteristics of jet wall-impingement of a natural-gas jet (14-20 bar) combined with higher diesel injection pressure $(500,600$ and 700 bar) into a constant-volume chamber were extensively investigated under different pressures, injector-wall distances and wall temperatures using the Schlieren system. The obtained images were processed using MATLAB software.

\section{Experimental methods}

\subsection{Experimental test rig}

A chamber, $88 \mathrm{~mm}$ high and $74 \mathrm{~mm}$ wide, was designed and built to allow for optical analysis of diesel-CNG dual fuel jet-wall impingement. The bottom plate of the test rig was made from aluminium (piston material) with a thermocouple while the sides were made from tempered glass. Different methods were used in previous studies for achieving representative temperature conditions in the rig e.g. some used direct heating of the walls (bottom) of the test rig [5, 7], while others used an electric heater [9] inside the plate. In this study, a controlled electric heater was used to heat the bottom plate up to $500 \mathrm{~K}$. A holder of the diesel and CNG injectors was mounted in the center of test 
rig's top plate which was moved up and down to vary the injector-wall distance in the range 80-40 $\mathrm{mm}$. Before the experiment started, the temperature distribution inside the rig was measured and showed that there was a moderate gradient from bottom to top. When the bottom plate was heated up to $500 \mathrm{~K}$, the temperature variations were $72,64,60$ and $54 \mathrm{~K}$ at $20,40,60$ and $80 \mathrm{~mm}$ from the bottom plate respectively.

\subsection{CNG Injection System}

The natural gas found in Malaysia which consists mainly of methane, ethane and propane was used in this project. A National Instrument driver and a power supply $(12 \mathrm{~V})$ were used to drive the injectors (diesel and CNG) with injection duration (solenoid valve opening) $5 \mathrm{~ms}$. The images were captured using the Schlieren system which consisted of a lamp, two concave mirrors, a knife edge and a high speed video camera (Phorton, FASTCAM-APX).

\subsection{Diesel injection system}

A common rail, electronically controlled injector system was used to generate and induce the high injection pressure sprays into the chamber. This injection system provided flexibility in controlling the injection timing, injection duration and the rail pressure. The fuel injection equipment included: an electric motor, a control unit, a high pressure fuel pump, a high pressure delivery pipe, a common rail, a regulator valve, a pressure gage, an injector driver and an injector. The fuel pump powered by an electric motor (the speed of motor was $1420 \mathrm{rev} / \mathrm{min}$ ) which was controlled through an electronic control unit $(\mathrm{ECU})$. To ensure stable set rail pressure, a pressure regulator valve and pressure gage were used. An injector driver circuit was built and used to control the opening and closing of the injector valve by which we were able to control the injection timing and injection duration which was built into a lab VIEW program. In order to study a single fuel spray, different researchers modified their injectors from different numbers of holes to study a single-hole nozzle [3-5, 9]. D. A. Kennaird et al. [3] in their study of multi-hole and single hole injectors spray penetration characteristics found that, single-hole injector was valid to characterize spray. Therefore, the injector used in this study was modified from 6 to a single-hole $(0.3 \mathrm{~mm}$ diameter $)$ to characterize the axial spray penetration. The chosen injection pressures in this study were: 500, 600 and 700 bar.

\subsection{Image Processing}

The captured images were processed in order to calculate the jet radial penetration and jet height. The spray edges were detected by using a digital imaging program using a specified threshold level to distinguish the spray edges from background. Figure 1 shows how the jet radial penetration and jet height were defined.

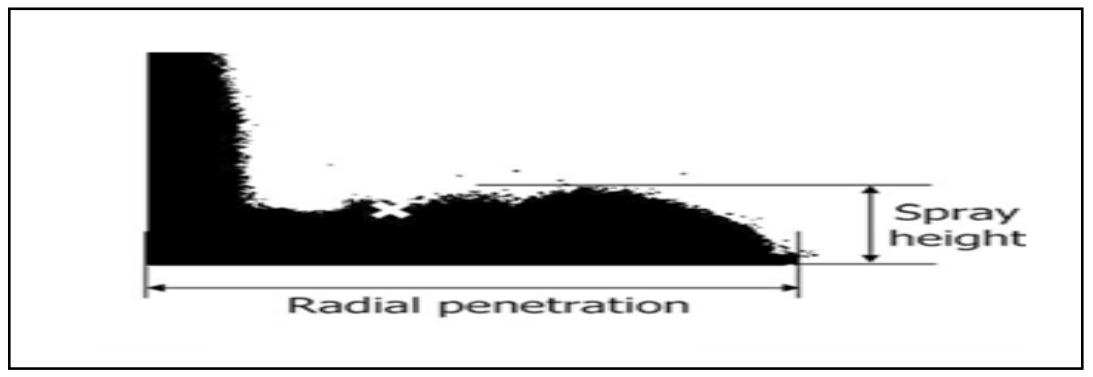

Figure 1. Definitions of spray radial penetration and spray height 


\section{Results and Discussion}

Place the figure as close as possible after the point where it is first referenced in the text. If there is a large number of figures and tables it might be necessary to place some before their text citation.

\subsection{Effects of Wall impingement on the diesel-CNG dual fuel jet development}

The development of the diesel and diesel-CNG dual fuel jet on the radial penetration along the wall and the jet height are presented in Figure 2. The injection pressures of diesel and CNG were 600 bar and 18 bar respectively at ambient wall temperature of $300 \mathrm{~K}$. It can be seen that the diesel-CNG dual fuel had a higher radial penetration than that of pure diesel. This phenomenon can be reasoned as following: as the pure diesel spray approaches the wall, it losses axial velocity caused by the interaction between the liquid and the wall, while in in the case of diesel-CNG dual fuel, the axial velocity was enhanced by the $\mathrm{CNG}$ jet resulting in a higher radial penetration on the wall. On the other hand, for the jet height, the pure diesel spray showed higher height than that of diesel-CNG dual fuel. This was probably due to the CNG jet having a lower density and thus easily mixed with ambient air while the diesel focused on the wall. The findings of this work are consistent with other results sets reported in literature [10].

\subsection{Effect of injection pressure on the radial penetration}

The effects of injection pressure on the jet radial penetration along the wall of the diesel and dieselCNG dual fuel are shown in Figure 3. In this figure, only the injection pressure for the diesel fuel was varied (500, 600 and 700 bar) because the CNG pressure variation was found to have very small effect in comparison to the diesel pressure. As shown in the figure, both the diesel and diesel-CNG dual fuel showed higher radial penetration with high injection pressure which is a well-known phenomenon. But in comparison between the single and dual fuel, the pure diesel radial penetration was largely affected by increasing the injection pressure rather than that of diesel-CNG. This trend indicates that the diesel fuel loses its momentum by vortices of CNG [11].

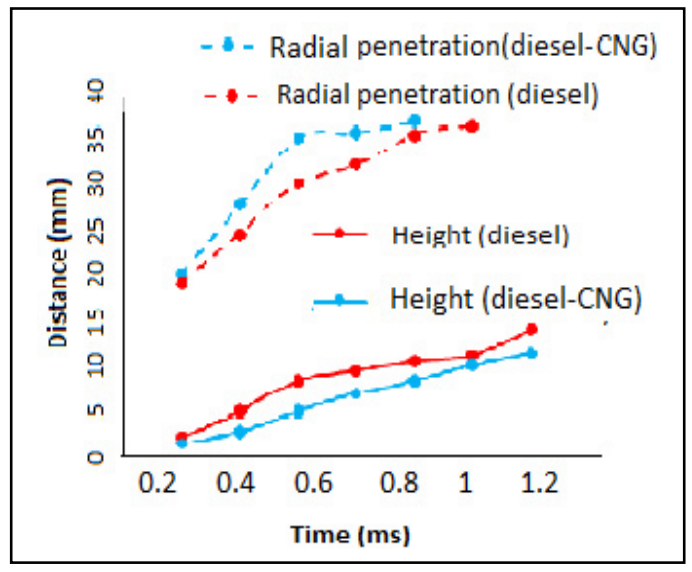

Figure 2. The radial penetration and height of diesel and diesel-CNG dual fuel jet impinged on the wall (inj. $\mathrm{P}=600 \mathrm{bar}$ for diesel and 18 bar for $\mathrm{CNG}$ and injector the wall distance: $60 \mathrm{~mm}$ and the wall temperature $300 \mathrm{~K}$ ).

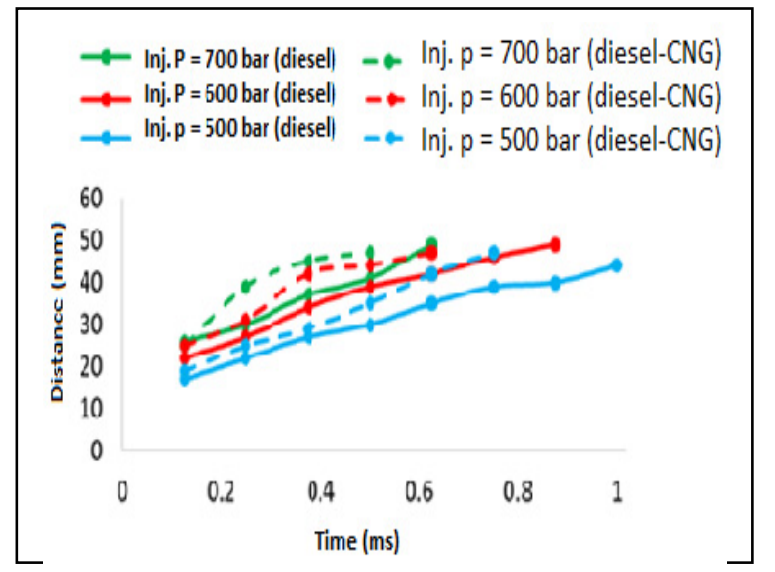

Figure 3. Effect of injection pressure on the radial penetration of diesel and diesel-CNG dual fuel impinged on the wall at diesel and $\mathrm{CNG}$ injection pressures 600 bar and 18 bar respectively. 


\subsection{The effect of wall distance from the injector on the jet radial penetration}

Figure 4 shows the effect of distance from the injector to the wall $(80,60$ and $40 \mathrm{~mm})$ on the diesel and diesel-CNG dual fuel radial penetration along the wall respectively. It can be seen that both the diesel (single fuel) and the diesel-CNG dual fuel have a smaller radial penetration at a longer wall distance. This is because the jet velocity becomes lower as it moves downstream. In comparison to the diesel and the diesel-CNG dual-fuel, the wall distance had a higher effect on the pure diesel spray than that of the dual fuel. This is probably caused by the effect of the CNG in the axial direction which enhanced the diesel spray. Also, it can be seen that the differences in the radial penetration between the wall distance of $80 \mathrm{~mm}$ and $60 \mathrm{~mm}$ was small in comparison to the differences between wall distance of $60 \mathrm{~mm}$ and $40 \mathrm{~mm}$. The reason is because the impinging velocities of the jet decreased rapidly in the axial direction until it reached $40 \mathrm{~mm}$ in comparison to the decrease in the velocity beyond this distance. These results have been compared and verified with the findings from Lee and Lee[12], Park and Lee [10] and Andreassi et al. [13]. It was found to be in agreement with Park and Lee.

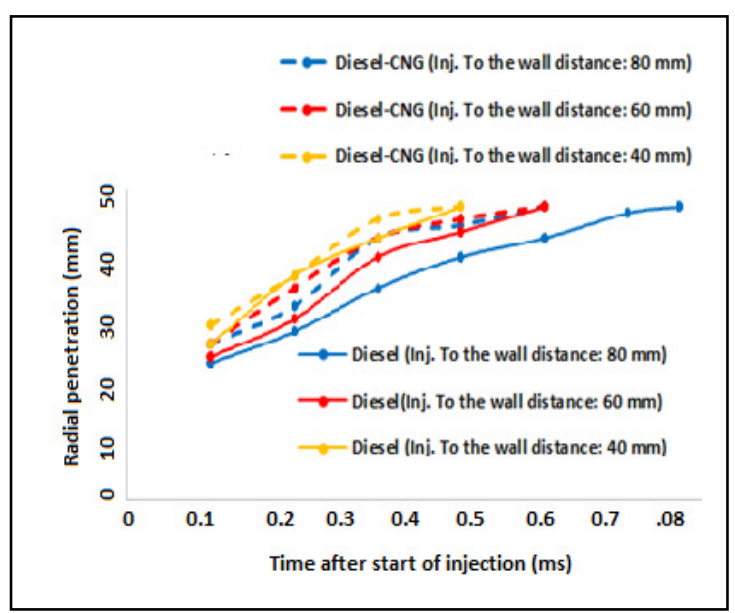

Figure 4. Effect of injector-wall distance on the radial penetration of the diesel spray at injection pressure 600 bar.

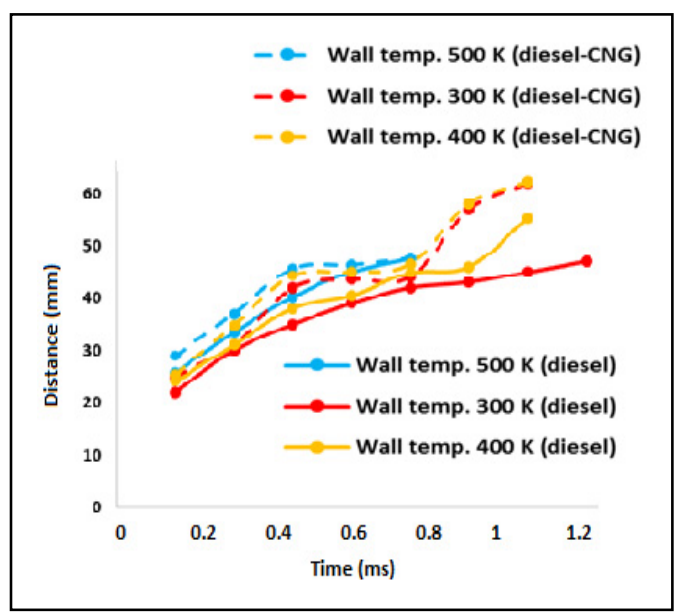

Figure 5. Effect of different wall temperatures on the radial penetration of diesel and dieselCNG dual fuel impinged on the wall.

\subsection{The effect of wall temperature on the diesel and diesel-CNG dual fuel radial penetration}

The spray radial penetrations along the wall of the diesel and diesel-CNG dual fuel under different wall temperatures $(300,400$ and $500 \mathrm{~K}$ ) are given in Figure 5. As shown in these figures, as expected, both single and dual fuel radial penetrations were slightly longer at higher wall temperature because the ambient gas density decreased with an increase in the ambient temperature [12]. As time elapsed, the temperature effects were higher in pure diesel spray than that of the dual fuel. This is due to the larger mass of the diesel-CNG dual fuel which resulted in lower temperature effect.

\section{Conclusion}

Two types of injectors have been used to characterize the propagations of CNG jets and Diesel-CNG dual-fuel jets namely a CNG electronic injector and a high pressure common rail diesel injector. The jet wall-impingement of the diesel-CNG dual-fuel was observed to be higher in the radial penetration as compared to pure diesel fuel. On the other hands, the pure diesel radial penetration was largely affected by increasing the injection pressure and temperature rather than that of diesel-CNG. 


\section{References}

1. R. A. Bakar, A. A. Aziz, and M. A. Sera, "Effect of Air Fuel Mixer Design on Engine Performance and Exhaust Emission Of A CNG Fuelled Vehicles," 2nd World Engineering Congress, pp. 22-25, (2002)

2. T. Korakianitis, Progress in Energy and Combustion Science, 37(1), pp. 89-112. (2011)

3. D. Kennaird, C. Crua, J. Lacoste, and M. Heikal, "In-cylinder penetration and break-up of diesel sprays using a common-rail injection system," SAE Technical Paper 2002-01-1626. (2002)

4. P. Raghu, European Journal of Scientific Research, 81(3), pp. 386-396. (2012)

5. M. Mittal, D. L. S. Hung, G. Zhu, and H. J. Schock, Journal of Visualization, 14(2), 149-160, (2011)

6. T. Senoo, M. Sasaki, and M. Shioji, World Automotive Congress, c, (2010)

7. J. Yu, H. Hillamo, T. Sarjovaara, and T. Hulkkonen, Journal of Physics, 1-14. (2011)

8. Y. Shim, G. Choi, and D. Kim, International Journal of Automotive Technology, vol. 9(3), 267275. (2008)

9. M. Mbarawa, B. Milton, and R. Casey, International Journal of Thermal Sciences, 729, 927-936. (2001)

10. S. Park and C. Lee, Experiments in fluids, vol. 37, no. 5, pp. 745-762, Sep. 2004.

11. R. Ding, J. Revstedt, and L. Fuchs, Proceedings of PSFVIP-4 (Chamonix) F 4015, 1-13, (2003)

12. C. H. Lee and K. H. Lee, International Journal, vol. 9, no. 3, pp. 373-380, 2008.

13. L. Andreassi, S. Ubertini, and L. Allocca, International Journal of Multiphase Flow, 33(7), 742765., (2007) 